\title{
SHOX duplications found in some cases with type I Mayer-Rokitansky-Kuster-Hauser syndrome
}

\author{
Cristina Gervasini, PhD ${ }^{I}$, Francesca Romana Grati, PhD ${ }^{2}$, Faustina Lalatta, MD ${ }^{3}$, Silvia Tabano, PhD ${ }^{I}$, \\ Barbara Gentilin, $M D^{3}$, Patrizia Colapietro, $P h D^{1}$, Simona De Toffol, PhD', Giada Frontino, MD ${ }^{4}$,

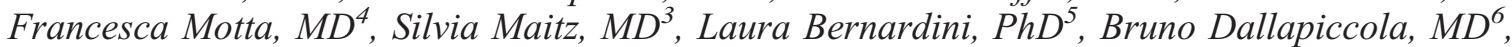 \\ Luigi Fedele, $M D^{4}$, Lidia Larizza, $M D^{I}$, and Monica Miozzo, PhD ${ }^{I}$
}

\begin{abstract}
Purpose: The Mayer-Rokitansky-Küster-Hauser syndrome is defined as congenital aplasia of müllerian ducts derived structures in females with a normal female chromosomal and gonadal sex. Most cases with MayerRokitansky-Küster-Hauser syndrome are sporadic, although familial cases have been reported. The genetic basis of Mayer-RokitanskyKüster-Hauser syndrome is largely unknown and seems heterogeneous, and a small number of cases were found to have mutations in the WNT4 gene. The aim of this study was to identify possible recurrent submicroscopic imbalances in a cohort of familial and sporadic cases with Mayer-Rokitansky-Küster-Hauser syndrome. Methods: Multiplex ligation-dependent probe amplification was used to screen the subtelomeric sequences of all chromosomes in 30 patients with Mayer-RokitanskyKüster-Hauser syndrome (sporadic, $n=27$ and familial, $n=3$ ). Segregation analysis and pyrosequencing were applied to validate the MLPA results in the informative family. Results: Partial duplication of the Xpter pseudoautosomal region 1 containing the short stature homeobox $(S H O X)$ gene was detected in five patients with Mayer-Rokitansky-Küster-Hauser syndrome (familial, $n=3$ and sporadic, $n=2$ ) and not in 53 healthy controls. The duplications were not overlapping, and SHOX was never entirely duplicated. Haplotyping in the informative family revealed that $S H O X$ gene duplication was inherited from the unaffected father and was absent in two healthy sisters. Conclusions: Partial duplication of SHOX gene is found in some cases with both familial and sporadic Mayer-Rokitansky-Küster-Hauser type I syndrome. Genet Med 2010:12(10):634-640.
\end{abstract}

Key Words: $M R K H, S H O X, M L P A, P A R 1$, müllerian aplasia

$\mathrm{T}$ he müllerian ducts are the anlage of the female reproductive tract. They differentiate to form the Fallopian tubes, the uterus, the uterine cervix, and the upper vagina. Disruption of the mor-

From the ${ }^{1}$ Medical Genetics, Department of Medicine, Surgery and Dentistry, Università degli Studi di Milano; ${ }^{2}$ Unit of Research and Development, Cytogenetics and Molecular Biology, TOMA Advanced Biomedical Assays S.p.A., Busto Arsizio, Varese; ${ }^{3}$ Department of Obstetrics and Pediatrics, Clinical Genetic Unit, Fondazione IRCCS Ospedale Maggiore Policlinico, Mangiagalli e Regina Elena, Milano; ${ }^{4}$ Department of Obstetrics and Gynecology, Fondazione IRCCS Ospedale Maggiore Policlinico, Mangiagalli e Regina Elena, Milano; 5"Casa Sollievo della Sofferenza" Hospital, Mendel Laboratory, San Giovanni Rotondo; and ${ }^{6}$ Ospedale Pediatrico Bambino Gesù, IRCCS, Roma, Italy.

Monica Miozzo, PhD, Medical Genetics, Department of Medicine, Surgery and Dentistry, Università degli Studi di Milano, via A. di Rudinì 8, Milano 20142, Italy. E-mail: monica.miozzo@unimi.it.

Cristina Gervasini and Francesca Romana Grati contributed equally to the work.

Disclosure: The authors declare no conflict of interest.

Submitted for publication March 11, 2010.

Accepted for publication June 15, 2010.

Published online ahead of print September 16, 2010.

DOI: 10.1097/GIM.0b013e3181ed6185 phogenetic process results in a wide variety of malformations. Complete müllerian aplasia or hypoplasia is known as MayerRokitansky-Küster-Hauser (MRKH) syndrome (OMIM \#277000). This disorder is characterized by malformations of the structures derived from the müllerian ducts. MRKH syndrome is the second most common cause of primary amenorrhoea and has an incidence of approximately 1 in 5000 female live births. ${ }^{1}$

MRKH syndrome may occur as an isolated abnormality (MRKH type 1 syndrome). However, in around $15-40 \%$ of the cases it is associated with some skeletal or urological malformations (MRKH type II syndrome), including (i) the KlippelFeil syndrome (OMIM \#118100, \#214300), ${ }^{2}$ characterized by congenital fusion of the cervical spine, short neck, low posterior hairline, and limited motion of the cervical spine and (ii) müllerian aplasia, renal aplasia, and cervicothoracic somite dysplasia (MURCS; OMIM \#601076). Rarely associated abnormalities include auditory and/or cardiac defects. ${ }^{3,4}$ This wide spectrum of associated anomalies suggests the involvement of structures derived from the intermediate mesoderm including kidneys and female internal genitalia. Patients with MRKH syndrome have a normal 46,XX karyotype, although rare X chromosomal abnormalities have been reported in association with gonadal dysgenesis. ${ }^{5-12}$

Although most cases are sporadic, a number of familial cases have been described, raising the possibility that a subset of patients with MRKH syndrome are the result of a single-gene disorder, as reviewed by Guerrier et al. ${ }^{13}$

Shokeir ${ }^{14}$ investigated 10 families with several members affected by MRKH syndrome. In the majority of them (8/10), there were some affected paternal relatives, raising the possibility of an autosomal dominant inheritance with sex-limited (female) expression and incomplete penetrance. It was suggested that female carriers develop müllerian abnormalities, whereas male carriers do not manifest any deleterious effect. ${ }^{14}$

The genetic basis of MRKH syndrome is largely unknown. Array-comparative genomic hybridization $(\mathrm{CGH})$ analyses have detected submicroscopic imbalances at 1q21.1, 4q34-qter, 17q12, 22q11.21, and Xq21.31. ${ }^{15,16}$ Recurrent changes have also been identified at 22q11q21.1 and 17q12.1,15-17 However, analysis of candidate genes have been inconclusive. ${ }^{10,13,15}$ Investigated loci include antimüllerian hormone and its receptor CTNNB $1^{18,19}$ and genes involved in early development such as $W T 1,{ }^{20} P A X 2,{ }^{20} H O X,{ }^{21,22} L M X 1$, and TCF $2 .{ }^{15}$ Mutations in the WNT4 gene have been found in four unrelated patients with MRKH syndrome with clinical signs of hyperandrogenism ${ }^{23-25}$ (OMIM \#158330), suggesting that MRKH syndrome with hyperandrogenism may be a clinical and genetic distinct disorder. However, given the low number of identified cases, it is unlikely that WNT4 plays a major role in the etiology of MRKH syndrome.

Taken together, these results suggest that MRKH syndrome is a clinically and genetically heterogeneous disorder. 
This report describes the molecular genetic investigation of a cohort of 30 women presenting with MRKH type I or type II syndrome. Our cohort included one family in which two of four sisters were affected by MRKH type I syndrome. This family was investigated using multiplex-ligation-dependent-probe-amplification (MLPA) to screen for imbalances at the subtelomeric regions of autosomes and sex chromosomes. A partial duplication of the gene $S H O X$ was detected in the two probands and their father. The analysis was, therefore, extended to include other 28 patients with MRKH syndrome of the cohort.

The SHOX gene is a member of the paired homeobox family and is located in the pseudoautosomal region 1 (PAR1) of chromosomes X and Y. SHOX controls fundamental aspects of growth and development, and its mutations have been associated with three distinct phenotypes: (i) Leri-Weill Dyschondrosteosis (OMIM \#127300), a dominantly inherited skeletal dysplasia characterized by moderately short stature secondary to short mesomelic limb segments and Madelung wrist deformities; (ii) Langer Mesomelic Dysplasia (OMIM \#249700), a rare recessive skeletal dysplasia characterized by extremely short stature secondary to shortening and malformation of the mesomelic and rhizomelic segments of the limbs; and (iii) idiopathic short stature (OMIM \#30058226).

The results of this study suggest that the SHOX gene is also implicated in both familial and sporadic type I MRKH syndrome.

\section{PATIENTS AND METHODS}

With regard to human subjects, we followed the guidelines of the ethical committee of the University of Milan (http://www. unimi.it/cataloghi/comitato_etico/CE_Rec_4_HBMs.pdf).

Table 1. Clinical data of patients with MRKH syndrome

\begin{tabular}{lr}
\hline Enrolled patients & 30 \\
Mean age at diagnosis (yr) & 22 \\
MRKH type I & 15 \\
MRKH type II & 14 \\
MURCS & 1 \\
Mean weight (kg) & 55 \\
Mean height (cm) & 161 \\
Mean BMI & 21 \\
Mean head circumference (cm) & 55 \\
Patients with hyperandrogenism & 12 \\
\hline
\end{tabular}

\section{Patients}

A total of 30 patients with MRKH syndrome were enrolled in the study after informed consent. The cohort included an affected sib-pair and one patient with a family history positive for MRKH syndrome. The other 27 patients were sporadic patients. Diagnostic criteria for MRKH syndrome included normal external genitalia, presence of pubic and axillary hair, absence of a vagina, presence of mullerian remnants, and no cystic swelling secondary to retained menstrual blood. The following auxologic data were collected: height, weight, body mass index (BMI), head circumference, arm span, span to height ratio, hand length, middle finger length, foot length, internal and external interchantal distance, and ear length. The relevant clinical data are summarized in Table 1. Neither severe abnormalities nor dysmorphic features were observed. All patients underwent ultrasonography of the pelvis and urinary system, pelvic magnetic resonance imaging, and karyotyping. Patients were classified as having type I or type II MRKH syndrome according to the absence or presence of other genitourinary malformations. Type II patients included (i) MURCS and (ii) MRKH syndrome associated with other clinical findings. ${ }^{4}$ Mean age at diagnosis was 22 years (range: 16-33 years). The patients showed no evidence of cognitive dysfunction.

\section{Familial patients}

Family 1 . Family 1 was composed of six members. The parents were healthy and nonconsanguineous. Two paternal aunts were reported to be infertile. However, they were not available for the study, and no additional information was available. Two of the four daughters had MRKH type I syndrome (Patients II-3 and II-4). At inclusion into the study, one sister was underweight $(\mathrm{BMI}=16.6)$, and the other was severely underweight $(\mathrm{BMI}=$ 13.3) (Table 2). All other parameters, including height and head circumference, were within the normal range. The affected sisters and their father had a normal karyotype.

Family 2. Family 2 was composed of four members. The parents were healthy and nonconsanguineous. Both daughters had MRKH type I syndrome. One sister refused to participate in the study. The auxologic and morphologic data of the investigated sister were within the normal range (Table 2). The patient showed clinical signs of hyperandrogenism (hirsutism and acne) and had a normal karyotype.

\section{Sporadic patients}

This cohort included 27 women who had been referred for management of primary amenorrhea. Twenty-six patients were Italians, and one was Filipino. Twelve patients were classified as having MRKH type I syndrome (Table 1). The remaining 15 patients were classified as having MRKH type II syndrome

Table 2. Diagnosis and main clinical features of patients with MRKH type 1 syndrome heterozygous for partial SHOX gene duplications

\begin{tabular}{lcccccc}
\hline Patients & Age at diagnosis $(\mathrm{yr})$ & Weight $(\mathrm{kg})$ & Height $(\mathrm{cm})$ & BMI & Head circumference $(\mathrm{cm})$ & Hyperandrogenism \\
\hline 1 & 19 & 49 & 1.65 & 14.8 & 55 & 53 \\
No \\
2 & 30 & 44 & 1.54 & 14.3 & 57 & Yes \\
3 & 29 & 56 & 1.68 & 16.7 & 54 & No \\
II-3 & 25 & 42 & 1.58 & 13.3 & 58 & No \\
II-4 & 23 & 53 & 1.60 & 16.6 & & 5 \\
\hline
\end{tabular}


(MURCS $n=1$, Table 1; MRKH syndrome with additional clinical findings $n=14$ ). Twenty-four percent of the patients had skeletal defects and $14 \%$ urinary tract malformations. Eleven patients showed clinical features of hyperandrogenism. All patients had a normal female karyotype $(46, X X)$.

Six patients reported a positive family history of dysmorphism, malformations, or mental retardation. In the remaining patients, the family history was unremarkable.

\section{Molecular analysis}

Genomic DNA was extracted from blood lymphocytes using the QIAamp DNA Mini Kit (Qiagen, Inc., Chatsworth, CA) in accordance with the manufacturer's instructions. Genomic DNA was obtained for all 30 patients, 53 healthy controls, and the parents from Family 1.

\section{WNT4 mutational analysis}

Patients with signs of hyperandrogenism $(n=12)$ were analyzed by direct sequencing of all WNT4 gene exons using polymerase chain reaction (PCR) primers, as reported previously. 24

\section{MLPA analysis}

MLPA analysis was performed using two commercial kits (MRC-Holland, Amsterdam, NL): P036 and P070, specific for all subtelomeres; P018 SHOX probe mix containing probes for each exon of the SHOX gene and several probes for regions upstream and downstream of the SHOX gene that have been implicated in its transcriptional regulation. The P018 SHOX probe mix was used only in a selected number of patients. The kits were used in accordance with the manufacturer's instructions, as described previously. ${ }^{27-29}$ Five normal DNA samples were included as references for the statistical analysis. Each patient was tested in parallel with a further wild-type sample and control samples from cytogenetically abnormal patients comprising autosome and sex chromosome aneuploidy. PCR products were separated using an ABIPRISM 3130 automatic sequencer and analyzed using GeneMapper software (Applied Biosystem, Foster City, CA). The MRC Coffalyser MLPADAT software was used for the normalization and statistical analysis of MLPA fragment data files, in accordance with the manufacturer's protocol. All results were confirmed by performing a second independent MLPA experiment.

DNA from 53 healthy and fertile females (a total of $106 \mathrm{X}$ chromosomes) was also tested with the P018 SHOX kit. These were used as reference samples to evaluate the presence, location, and frequency of copy number polymorphisms detected by the MLPA probes in patients. Probe positions are indicated in Figure 1 .

\section{Haplotyping}

Genotyping was performed in Family 1 using a panel of singlenucleotide polymorphisms (SNPs) located in the PAR1. These included four SHOX intragenic SNPs. The SNPs were selected using the NCBI database (available at: www.ncbi.nlm.nih.gov), and their positions are indicated in Figure 2. Loci and primers are available on request. PCR products were detected using an ABI PRISM 3130 sequencer (Applied Biosystem, Foster City, $\mathrm{CA})$. Electropherogram analyses were performed using Sequence Navigator and ChromasPro software.

\section{Pyrosequencing}

To confirm SHOX duplications by the assessment of allelic imbalance, DNA from informative patients was analyzed using a PyroMark ID instrument (Biotage AB, Uppsala, Sweden).
Loci and primers are available on request and their positions are shown in Figure 2A.

Data quantification was performed using PyroMark ID software v1.0.9 (Biotage AB). This calculates the ratio of each allele as a percentage. For each sample, allelic contribution values represented the mean of at least two independent PCR and Pyrosequencing analyses.

\section{RESULTS}

No WNT4 mutations were identified in the 12 patients with clinical signs of hyperandrogenism.

Partial SHOX duplications were detected in five of the 30 patients with MRKH syndrome. These included the two affected sisters of Family 1, the available familial patient from Family 2, and two sporadic patients.

\section{Molecular results of the cohort}

In five patients with MRKH syndrome, subtelomeric MLPA analysis demonstrated changes in the Xp telomeric region. Refined analysis using the $S H O X$-specific P018 MLPA kit revealed differing partial $S H O X$ gene duplications in three patients (one familial and two sporadic) compared with those identified in the affected sib-pair from Family 1. Figure 1 summarizes the duplicated regions identified in the familial and the sporadic patients.

\section{Family 1}

In Patients II-3 and II-4 (Family 1), probes 1148-L1331 and 3714-L0910, which were included in the two subtelomeric MLPA kits, showed values of $>1.3$. This result is compatible with the presence of a terminal Xp duplication. DNA from the parents and two healthy sisters (II-1 and II-2) was also analyzed. Normal range values (0.7-1.3) were obtained for DNAs from II-1 and II-2. A signal pattern of $>1.3$ was obtained for both probes for the paternal DNA (data not shown). The P018 kit was then used in all members of Family 1 to confirm and refine the imbalanced region because these probes mapped to the PAR1 at 0.57 and $0.50 \mathrm{Mb}$ from the Xp telomere at different positions in the SHOX gene (Fig. 1). A signal pattern consistent with a duplication of exons 4, 5, and 6, involving probes 1148-L1331, 1149-L0910, 1150-L0911, 1151-L0708, and 1152-L0709 was detected in the two affected sisters and in the paternal DNA (Figs. 1 and 2). The size of the duplicated region was estimated at approximately $17 \mathrm{~kb}$ (Fig. 1), based on the position of probes displaying normal signals flanking the probes with abnormal signals.

\section{Patient 1 (sporadic)}

In Patient 1, a de novo duplication of the region marked by probes 1145-L0702 (SHOX exon 1) and 1146-L6220 (SHOX exon 2) was identified. The size of this duplication was approximately $7 \mathrm{~kb}$ (Fig. 1).

\section{Patient 2 (Family 2)}

In Patient 2, who was one of the affected daughters from Family 2, a duplication of $>290 \mathrm{~kb}$ (Fig. 1), spanning between 2726-L1588 probe (located in PPP2R3B) and 1147-L0802 probe (in $S H O X$ exon 3), was identified.

\section{Patient 3 (sporadic)}

In Patient 3, a duplication of $>300 \mathrm{~kb}$, spanning between 2726-L1588 probe (in PPP2R3B) and 1151-L0708 probe (located at the $3^{\prime}$ of the SHOX gene), was identified (Fig. 1). Because of the lack of MLPA probes telomeric to 2726-L1588, 
A
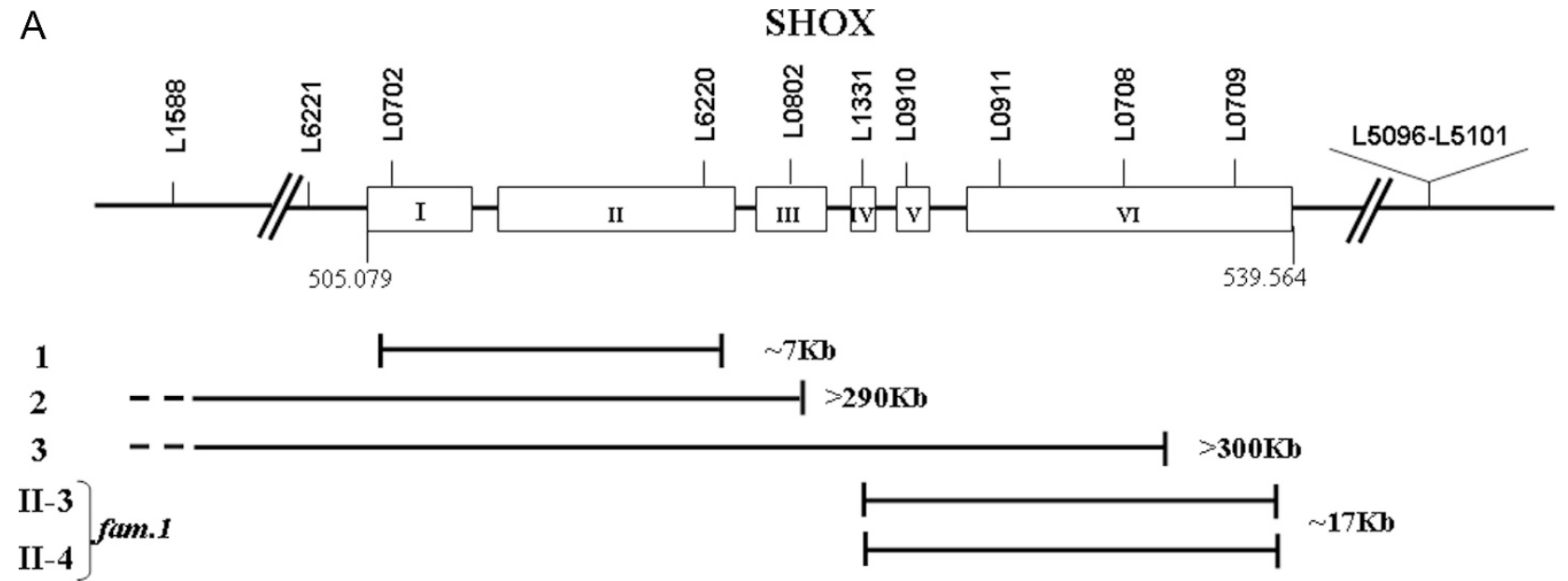

B

\begin{tabular}{|c|c|c|c|c|c|c|c|c|c|c|c|c|c|}
\hline PROBE & |probe position & physical map & I-1 & I-2 & II-1 & II-2 & II-3 & II-4 & 1 & 2 & 3 & $45, X$ & $47, \mathrm{XXY}$ \\
\hline $2726-\mathrm{L} 1588$ & PPP2R3B & $227444-227467$ & $\mathrm{~N}$ & N & $\mathrm{N}$ & $\mathrm{N}$ & $\mathrm{N}$ & $\mathrm{N}$ & $\mathrm{N}$ & DUP & DUP & DEL & DUP \\
\hline 1341-L6221 & LOC159015 & $500456-500479$ & $\mathrm{~N}$ & $\mathrm{~N}$ & $\mathrm{~N}$ & N & $\mathrm{N}$ & $\mathrm{N}$ & $\mathrm{N}$ & DUP & DUP & DEL & DUP \\
\hline 1145-L0702 & SHOXa exon 1 & $505166-505189$ & $\mathrm{~N}$ & $\mathrm{~N}$ & $\mathrm{~N}$ & $\mathrm{~N}$ & $\mathrm{~N}$ & $\mathrm{~N}$ & DUP & DUP & DUP & DEL & DUP \\
\hline $1146-\mathrm{L} 6220$ & SHOXa exon 2 & $511850-511873$ & $\mathrm{~N}$ & $\mathrm{~N}$ & N & N & $\mathrm{N}$ & $\mathrm{N}$ & DUP & DUP & DUP & DEL & DUP \\
\hline 1147-L0802 & SHOXa exon 3 & $515405-515428$ & $\mathrm{~N}$ & $\mathrm{~N}$ & $\mathrm{~N}$ & $\mathrm{~N}$ & $\mathrm{~N}$ & $\mathrm{~N}$ & $\mathrm{~N}$ & DUP & DUP & DEL & DUP \\
\hline 1148-L1331 & SHOXa exon 4 & $521565-521588$ & $\mathrm{~N}$ & DUP & $\mathrm{N}$ & $\mathrm{N}$ & DUP & DUP & $\mathrm{N}$ & $\mathrm{N}$ & DUP & DEL & DUP \\
\hline 1149-L0910 & SHOXa exon 5 & $521748-521771$ & $\mathrm{~N}$ & DUP & $\mathrm{N}$ & $\mathrm{N}$ & DUP & DUP & $\mathrm{N}$ & $\mathrm{N}$ & DUP & DEL & DUP \\
\hline 1150-L0911 & SHOXa exon 6 & $525296-525319$ & $\mathrm{~N}$ & DUP & $\mathrm{N}$ & $\mathbb{N}$ & DUP & DUP & $\mathrm{N}$ & $\mathrm{N}$ & DUP & DEL & DUP \\
\hline 1151-L0708 & ATG & $531744-531767$ & N & DUP & $\mathrm{N}$ & $\mathrm{N}$ & DUP & DUP & $\mathrm{N}$ & $\mathrm{N}$ & DUP & DEL & DUP \\
\hline 1152-L0709 & STOP SHOXa & $538116-538139$ & $\mathrm{~N}$ & DUP & $\mathrm{N}$ & $\mathrm{N}$ & DUP & DUP & $\mathrm{N}$ & $\mathrm{N}$ & $\mathrm{N}$ & DEL & DUP \\
\hline 5642-L5096 & $\mathrm{Xp} 22.32-\mathrm{PAR}$ & $594959-594982$ & $\mathrm{~N}$ & $\mathrm{~N}$ & N & N & $\mathrm{N}$ & $\mathrm{N}$ & $\mathrm{N}$ & $\mathrm{N}$ & $\mathrm{N}$ & DEL & DUP \\
\hline 5643-L5097 & $\mathrm{Xp} 22.32-\mathrm{PAR}$ & $626171-626194$ & $\mathrm{~N}$ & $\mathrm{~N}$ & $\mathrm{~N}$ & $\mathrm{~N}$ & $\mathrm{~N}$ & $\mathrm{~N}$ & $\mathrm{~N}$ & $\mathrm{~N}$ & $\mathrm{~N}$ & DEL & DUP \\
\hline 5644-L5098 & $\mathrm{Xp} 22.32 \mathrm{PAR}$ & $686180-686203$ & $\mathrm{~N}$ & N & $\mathrm{N}$ & N & $\mathrm{N}$ & $\mathrm{N}$ & $\mathrm{N}$ & $\mathrm{N}$ & $\mathrm{N}$ & DEL & DUP \\
\hline 5645-L5099 & $\mathrm{Xp} 22.32 \mathrm{PAR}$ & $729273-729296$ & $\mathrm{~N}$ & N & $\mathrm{N}$ & $\mathrm{N}$ & $\mathrm{N}$ & $\mathrm{N}$ & $\mathrm{N}$ & $\mathrm{N}$ & $\mathrm{N}$ & DEL & DUP \\
\hline 5646-L5100 & $\mathrm{Xp} 22.32 \mathrm{PAR}$ & $737731-737754$ & $\mathrm{~N}$ & $\mathrm{~N}$ & $\mathrm{~N}$ & N & $\mathrm{N}$ & $\mathrm{N}$ & $\mathrm{N}$ & $\mathrm{N}$ & $\mathrm{N}$ & DEL & DUP \\
\hline $5647-\mathrm{L} 5101$ & $\mathrm{Xp} 22.32 \mathrm{PAR}$ & $743187-743210$ & $\mathrm{~N}$ & $\mathbb{N}$ & N & $\mathbb{N}$ & $\mathrm{N}$ & $\mathbb{N}$ & $\mathrm{N}$ & $\mathrm{N}$ & $\mathrm{N}$ & DEL & DUP \\
\hline
\end{tabular}

Fig. 1. MLPA results obtained with P018 SHOX probe mix (MRC Holland) on the Xp region in five patients with type I MRKH syndrome. A, Schematic representation of SHOX gene and its flanking regions. MLPA probes are positioned on the SHOX exons and 5' UTR and its flanking regions. The bars below the physical map indicate the various sized duplications observed in the familial patient 1 (Family 2), sporadic patients 2 and 3, and the two affected sisters (II-3 and II-4) of Family 1. For Patients 2 and 3, the telomeric boundary of the duplication was not defined (dashed lines) because the region was not covered by the MLPA probes. Physical position refers to Genomic Bioinformatic Group of University of California Santa Cruz (UCSC) Genome Browser on Human Mar. 2006 Assembly (hg18). B, Detailed list of the probe composition of P018 SHOX mix: the precise position of each probe is indicated, and the results for all members of Family 1 (including the two MRHK syndrome-affected sisters) and the other three patients with MRKH syndrome are shown. The last two columns refer to the positive controls (carriers of sex chromosome aneuploidies) for the deletion and the duplication of the whole targeted region.

it was not possible to establish the telomeric boundary of the duplication in Patients 2 and 3.

\section{Controls}

Analysis of DNA from the 53 healthy female controls using the P018 SHOX kit revealed no SHOX gene duplications. In six controls, probe signal patterns of $>1.3$ beyond the $S H O X$ gene ( $>400 \mathrm{~kb}$ distance) were found for the following probes: 5650 L5104 (SHOX gene downstream and two controls), 5651-L5105 (SHOX gene downstream and two controls), 1170-L0710 (CSF2RA and one control), and 1153-L0712 (ASMT and one control). Analysis using the Database of Genomic Variants (available at: http://projects.tcag.ca/humandup/) indicated that the observed rearrangements were common polymorphisms.
Inheritance pattern of the SHOX duplication in Family 1

In Family 1, genotyping was performed using polymorphic markers in the PAR1 to trace the father-to-daughter inheritance of the region containing the $S H O X$ gene duplication.

The results are shown in Figure 2B. The two affected sisters and their father shared the same haplotype of the PAR1, including SHOX gene. The centromeric boundary of the shared region was marked by SNP rs28631450, which is located approximately $1 \mathrm{~kb}$ downstream of SHOX gene, as shown in Figure 2A.

To confirm the intragenic SHOX gene duplication detected in Patients II-3 and II-4, quantitative genotyping of the heterozygous intragenic SHOX SNPs was performed using pyrosequencing. This demonstrated that the paternal rs3748527 (intron 5) 


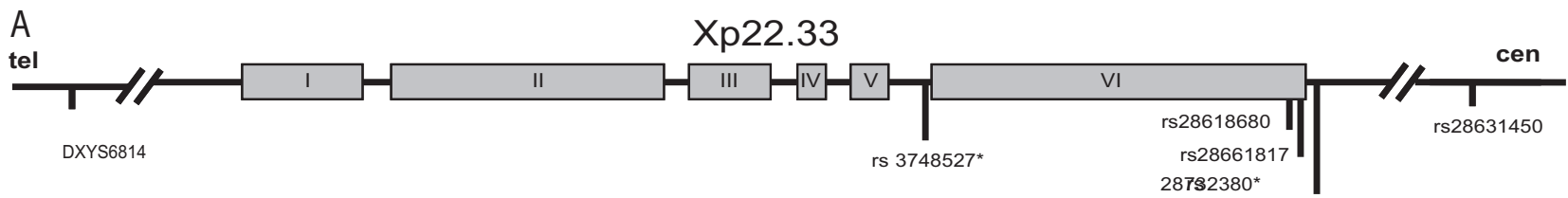

B

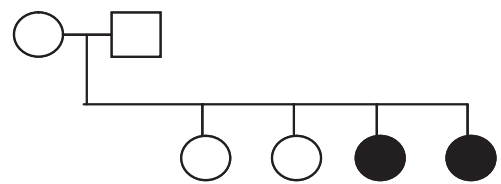

\begin{tabular}{ll|ll|ll|ll|ll|ll|l} 
DXYS6814 & 2 & 3 & 1 & 3 & 2 & 1 & 2 & 1 & 3 & 3 & 2 & 3 \\
rs $3748527^{*}$ & G & A & G & A & G & G & G & G & A & A & G & A \\
rs 28661817 & A & A & A & G & A & A & A & A & A & G & A & G \\
rs 28618680 & T & T & T & C & T & T & T & T & T & C & T & C \\
rs28732380* & A & T & A & A & A & A & A & A & T & A & A & A \\
rs 28631450 & A & A & A & G & A & G & A & G & A & G & A & A
\end{tabular}
C
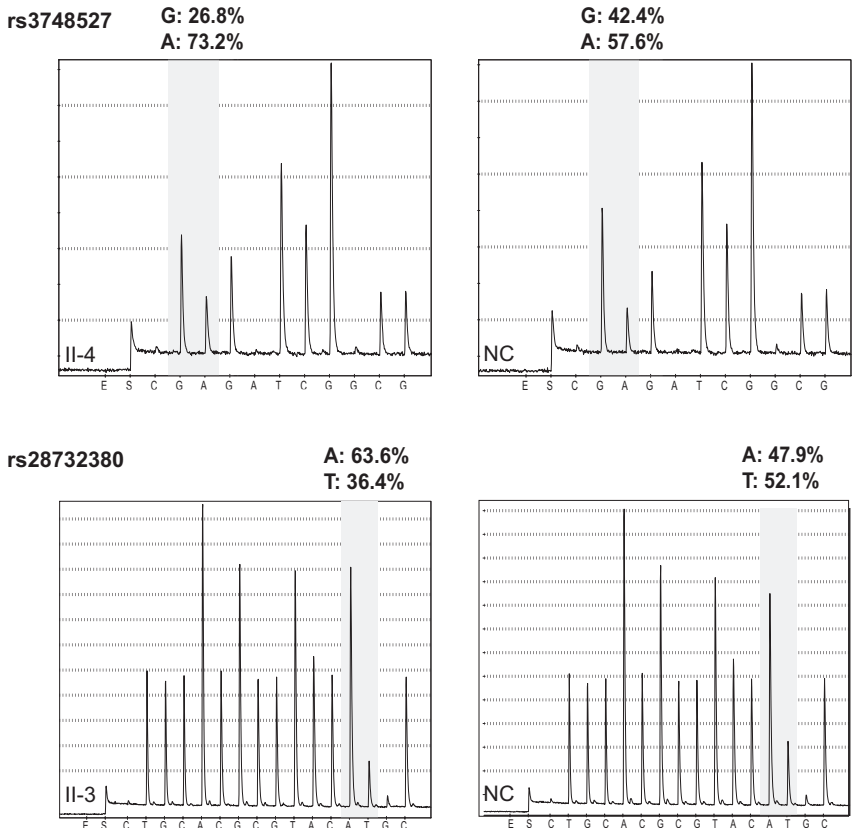

Fig. 2. Analysis of the SHOX region in Family 1. A, Representation of the SHOX genomic region. The positions of the polymorphisms used for the pyrosequencing $\left(^{*}\right)$ and haplotyping analyses are indicated. B, Segregation analysis using polymorphic markers encompassing the SHOX and flanking regions: the affected sisters (II-3 and II-4), but not the healthy sisters, inherited the haplotype containing the duplicated SHOX region from their father (shaded). C, Pyrograms of heterozygous SNPs located within SHOX gene of Patients II-3 and II-4 and one control (NC). The percentage of each allele contribution is indicated. Patients II-3 and II-4 show imbalances in the allele ratios, consistent with the presence of the duplication.

and rs28732380 (intron 6) alleles were present at a twofold dosage compared with the maternal alleles (Fig. 2C). Conversely, the contribution of the maternal and paternal alleles of the rs28475531, rs28574910, rs28433123, rs1894339, and rs2238842 loci, which are beyond and telomeric to the duplication, was balanced (data not shown).

The analysis was repeated in 10 normal control samples, which showed a balanced allele contribution for all heterozygous loci (data not shown).

\section{DISCUSSION}

The genetic basis of MRKH syndrome has been extensively investigated using a variety of approaches. These include (i) mutational analysis of candidate genes ${ }^{10,13,18-22}$; (ii) conventional cytogenetics, ${ }^{5-12}$ fluorescent in situ hybridization analysis $^{1}$; and (iii) investigation of whole genome imbalances by array-CGH. ${ }^{15,16}$ WNT4 mutations have been reported only in four patients all displaying hyperandrogenism, although most of the patients with this feature remain with an unknown etiology. ${ }^{23-25}$ The lack of $W N T 4$ mutations in all the 12 patients with hyperandrogenism belonging to the cohort here tested is consistent with these findings.

Although familial aggregations are a valuable resource for the identification of disease genes, no previous study of MRKH syndrome families has identified any underlying genetic lesion. ${ }^{13}$ This study used a two-step MLPA strategy (subtelomere screening and SHOX gene analysis) in a two-generation family with two MRKH type 1 syndrome sisters and healthy relatives (Family 1) to determine whether any subtelomeric imbalance cosegregated with the MRKH syndrome phenotype. A duplication of SHOX gene was detected and the involved genomic region (encompassing exons 4,5 , and a portion of exon 6) defined. This imbalance was shared by both sisters with MRKH syndrome and their healthy father but was lacking in the mother and the two unaffected sisters. In Family 1, the father showed no feature of MRKH syndrome (genital, renal, auricular, or skeletal anomalies). ${ }^{30,31}$ It is, therefore, plausible that this imbalance is not associated with any clinically significant anomaly in the transmitting males. Conception of the two MRKH syndrome-affected daughters involved paternal gametes carrying the imbalance, whereas conception of the two nonaffected sis- 
ters involved normal paternal gametes. This observation is consistent with the Shokeir's ${ }^{14}$ hypothesis arguing for a dominant transmission of MRKH syndrome from unaffected male carriers. The report of two infertile paternal aunts in the family described in this study is intriguing. Although it was not possible to assign a definite diagnosis of MRKH syndrome in these women, our family provides some support to the paternal origin of MRKH syndrome in some pedigrees.

Interestingly, application of the MLPA approach in 28 additional women with MRKH syndrome led to the identification of SHOX gene duplications in three unrelated patients. One of these patients was a familial case from Family 2 (the sister was affected by MRKH type I syndrome), whereas the other two patients were sporadic. These five patients heterozygous for SHOX gene duplications had a clinical diagnosis of MRKH type I syndrome. On the whole, of 15 patients with MRKH type I syndrome in this cohort, one third displayed SHOX gene duplications. This suggests that partial SHOX gene duplications are implicated in both familial and sporadic forms of MRKH type I syndrome. SHOX gene is located within the PAR1 (Xp22.33; Yp11.3) and displays an "autosomal" rather than a sex-linked inheritance. In common with other genes in this region, SHOX escapes $\mathrm{X}$ inactivation. In addition, SHOX is the only known disease gene within PAR1, and its loss of function mutations (point mutations or deletions) being causal factors of disorders of bone development ${ }^{26}$ including Leri-Weill dyschondrosteosis, Langer mesomelic dysplasia, and different forms of short stature. Three SHOX gene copies are found in some sex chromosome aneuplodies, which may be associated with tall stature in the absence of any distinct skeletal anomaly. ${ }^{26}$ SHOX gene is a member of the paired-related $H O X$ family, which is highly conserved among species. However, in contrast to other $H O X$ family genes, SHOX is absent in the mouse and in rodent species. $^{32} H O X$ genes have been considered candidates for MRKH syndrome being involved in the development of the müllerian ducts. ${ }^{33,34}$ However, mutations of $H O X$ genes in mouse do not result in a MRKH-like phenotype. ${ }^{35}$ This may be attributable to the absence of SHOX homologues in rodents.

SHOX gene encodes two differentially spliced mRNAs, SHOXA, and SHOXB. Its expression has been demonstrated in fetal and prepubertal growth plate chondrocytes. This is consistent with a role in bone development and final height. ${ }^{36} \mathrm{SHOXB}$ is expressed in fetal kidney tissue, which is closely involved in the development of the urogenital system. ${ }^{26,36}$ Although there have been frequent reports of deletions within the SHOX gene region, ${ }^{37-43}$ SHOX duplications are apparently very rare, only six cases having been described. ${ }^{39,44-46}$ In these cases, the duplications included the entire $S H O X$ gene coding region with different extragenic boundaries. No causal relationship between duplication of SHOX gene and any distinct phenotype has yet been established. Tachdjian et al. ${ }^{45}$ described a SHOX gene duplication in a woman with premature ovarian failure, which displayed a complex rearrangement including Xq21.31 deletion. Thomas et al., ${ }^{46}$ in describing a previously published patient ${ }^{39}$ and three novel families, hypothesized that complete SHOX gene duplications are associated with idiopathic tall stature. However, Roos et al. ${ }^{44}$ rejected the hypothesis of "susceptibility to tallness" while reporting a patient with SHOX gene duplication and normal growth.

It is unclear why $S H O X$ duplications are rare in comparison with $S H O X$ deletions, because duplications and deletions have a reciprocal relationship, and are the simultaneous products of nonallelic homologous recombination during meiosis. One hypothesis is that duplications may be subject to negative selection, because they induce infertility in women. It is also possible that duplications may be overlooked in the normal male carriers who have no affected female progeny. The rearrangements described in this study did not encompass the complete SHOX gene sequence but involved different $S H O X$ exons. MLPA screening of 53 healthy women and consultation of the Database of Genomic Variants (available at: http://projects.tcag.ca/humandup/) excluded any coincidental association between müllerian abnormalities and partial SHOX duplications.

In this cohort, none of the five patients with MRKH syndrome with a $S H O X$ gene duplication showed skeletal abnormalities, which are expected in individuals with SHOX gene haploinsufficiency, and height values were within the expected parental targets. Although the consequences of partial SHOX duplications at the protein level are unknown, it is likely that they result in the production of aberrant proteins. It may be hypothesized that a gain of function, interfering at a specific time point with early embryonic development, could be implicated in the development of MRKH syndrome rather than a loss of function resulting in absence of the gene product. This point should be investigated by targeted studies.

The data obtained in this study should encourage further investigation of MRKH type I syndrome and suggest the involvement of SHOX gene in müllerian structures development. Future investigations should define the significance of heterozygous SHOX duplications and elucidate the mechanisms underlying the dysruption of early müllerian structure development.

\section{ACKNOWLEDGMENTS}

This work was supported by a Grant from Progetto Fondazione IRCCS 2007-2008 (L.F.) and ASM 2007 (M.M.) (Associazione Italiana Studio Malformazioni onlus).

The authors are grateful to the patients and their family members. The authors thank the Galliera Genetic Bank, Network of Telethon Genetic Biobank, project GTB07001 for providing us with lymphoblastoid cell lines of the patients.

\section{REFERENCES}

1. Cheroki C, Krepischi-Santos AC, Rosenberg C, et al. Report of a del22q11 in a patient with Mayer-Rokitansky-Kuster-Hauser (MRKH) anomaly and exclusion of WNT-4, RAR-gamma, and RXR-alpha as major genes determining MRKH anomaly in a study of 25 affected women. Am J Med Genet A 2006;140:1339-1342.

2. Park IJ, Jones HW, Nager GT, Chen SC, Hussels IE. A new syndrome in two unrelated females: Klippel-Feil deformity, conductive deafness and absent vagina. Birth Defects Orig Artic Ser 1971;7:311-317.

3. Letterie GS, Vauss N. Mullerian tract abnormalities and associated auditory defects. J Reprod Med 1991;36:765-768.

4. Strubbe EH, Cremers CW, Dikkers FG, Willemsen WN. Hearing loss and the Mayer-Rokitansky-Kuster-Hauser syndrome. Am J Otol 1994;15:431436

5. Aydos S, Tukun A, Bokesoy I. Gonadal dysgenesis and the Mayer-Rokitansky-Kuster-Hauser syndrome in a girl with $46, \mathrm{X}, \operatorname{del}(\mathrm{X})(\mathrm{pter}->\mathrm{q} 22$ :) Arch Gynecol Obstet 2003;267:173-174.

6. De Leon FD, Hersh JH, Sanfilippo JS, Schikler KN, Yen FF. Gonadal and mullerian duct agenesis in a girl with 46,X,i(Xq). Obstet Gynecol 1984; 63(suppl 3):81S-83S.

7. Gardo S, Papp Z, Gaal J. XO-XX Mosaicism in the Rokitansky-KusterHauser syndrome. Lancet 1971;2:1380-1381.

8. Guitron-Cantu A, Lopez-Vera E, Forsbach-Sanchez G, Leal-Garza CH, Cortes-Gutierrez EI, Gonzalez-Pico I. Gonadal dysgenesis and Rokitansky syndrome. A case report. J Reprod Med 1999;44:891-893.

9. Linquette M, Gasnault JP, Dupont-Lecompte J, Hubschman B, Andre A. [Rokitansky-Kuster-Hauser and similar syndromes of uter-vaginal aplasia]. Rev Fr Endocrinol Clin 1968;9:41-60.

10. Morcel K, Camborieux L, Guerrier D. Mayer-Rokitansky-Kuster-Hauser (MRKH) syndrome. Orphanet J Rare Dis 2007;2:13.

11. Phansey SA, Tsai CC, Williamson HO. Vaginal agenesis in association with gonadal dysgenesis. Obstet Gynecol 1981;57(suppl 6):56S-57S.

12. Sarto GE. Cytogenetics of fifty patients with primary amenorrhea. Am J Obstet Gynecol 1974;119:14-23.

13. Guerrier D, Mouchel T, Pasquier L, Pellerin I. The Mayer-Rokitansky-Kuster- 
Hauser syndrome (congenital absence of uterus and vagina) - phenotypic manifestations and genetic approaches. J Negat Results Biomed 2006;5:1.

14. Shokeir MH. Aplasia of the mullerian system: evidence for probable sexlimited autosomal dominant inheritance. Birth Defects Orig Artic Ser 1978; $14: 147-165$

15. Bernardini L, Gimelli S, Gervasini C, et al. Recurrent microdeletion at $17 \mathrm{q} 12$ as a cause of Mayer-Rokitansky-Kuster-Hauser (MRKH) syndrome: two case reports. Orphanet J Rare Dis 2009;4:25.

16. Cheroki C, Krepischi-Santos AC, Szuhai K, et al. Genomic imbalances associated with mullerian aplasia. J Med Genet 2008;45:228-232.

17. Lindner TH, Njolstad PR, Horikawa Y, Bostad L, Bell GI, Sovik O. A novel syndrome of diabetes mellitus, renal dysfunction and genital malformation associated with a partial deletion of the pseudo-POU domain of hepatocyte nuclear factor-1beta. Hum Mol Genet 1999;8:2001-2008.

18. Drummond JB, Rezende CF, Peixoto FC, Carvalho JS, Reis FM, De Marco L. Molecular analysis of the beta-catenin gene in patients with the Mayer-Rokitansky-Kuster-Hauser syndrome. J Assist Reprod Genet 2008;25:511-514.

19. Zenteno JC, Carranza-Lira S, Kofman-Alfaro S. Molecular analysis of the anti-Mullerian hormone, the anti-Mullerian hormone receptor, and galactose-1-phosphate uridyl transferase genes in patients with the Mayer-Rokitansky-Kuster-Hauser syndrome. Arch Gynecol Obstet 2004;269:270-273.

20. van Lingen BL, Reindollar RH, Davis AJ, Gray MR. Further evidence that the WT1 gene does not have a role in the development of the derivatives of the mullerian duct. Am J Obstet Gynecol 1998;179:597-603.

21. Gendron RL, Paradis H, Hsieh-Li HM, Lee DW, Potter SS, Markoff E Abnormal uterine stromal and glandular function associated with maternal reproductive defects in Hoxa-11 null mice. Biol Reprod 1997;56:1097-1105.

22. Warot X, Fromental-Ramain C, Fraulob V, Chambon P, Dolle P Gene dosage-dependent effects of the Hoxa-13 and Hoxd-13 mutations on morphogenesis of the terminal parts of the digestive and urogenital tracts. Development 1997;124:4781-4791.

23. Biason-Lauber A, De Filippo G, Konrad D, Scarano G, Nazzaro A, Schoenle EJ. WNT4 deficiency - a clinical phenotype distinct from the classic MayerRokitansky-Kuster-Hauser syndrome: a case report. Hum Reprod 2007;22: 224-229.

24. Biason-Lauber A, Konrad D, Navratil F, Schoenle EJ. A WNT4 mutation associated with Mullerian-duct regression and virilization in a 46,XX woman. N Engl J Med 2004;351:792-798.

25. Philibert $\mathrm{P}$, Biason-Lauber A, Rouzier R, et al. Identification and functional analysis of a new WNT4 gene mutation among 28 adolescent girls with primary amenorrhea and mullerian duct abnormalities: a French collaborative study. J Clin Endocrinol Metab 2008;93:895-900.

26. Tiecke E, Bangs F, Blaschke R, Farrell ER, Rappold G, Tickle C. Expression of the short stature homeobox gene Shox is restricted by proximal and distal signals in chick limb buds and affects the length of skeletal elements. Dev Biol 2006;298:585-596.

27. Grati FR, Chinetti S, Malgara R, et al. Prenatal detection by subtelomeric FISH and MLPA of unbalanced meiotic recombinants resulting from parental pericentric inversions. Mol Cell Probes 2008;22:316-319.

28. Northrop EL, Ren H, Bruno DL, et al. Detection of cryptic subtelomeric chromosome abnormalities and identification of anonymous chromatin using a quantitative multiplex ligation-dependent probe amplification (MLPA) assay. Hum Mutat 2005;26:477-486.
29. Schouten JP, McElgunn CJ, Waaijer R, Zwijnenburg D, Diepvens F, Pals G. Relative quantification of 40 nucleic acid sequences by multiplex ligationdependent probe amplification. Nucleic Acids Res 2002;30:e57.

30. Meschede D, Kliesch S, Horst J, Nieschlag E. Azoospermia and segmentation abnormalities of the cervicothoracic spine ('MURCS in the male'). Clin Dysmorphol 1998;7:59-60.

31. Wellesley DG, Slaney SF. MURCS in a male? J Med Genet 1995;32:314315 .

32. Clement-Jones M, Schiller S, Rao E, et al. The short stature homeobox gene SHOX is involved in skeletal abnormalities in Turner syndrome. Hum Mol Genet 2000;9:695-702

33. Kobayashi A, Shawlot W, Kania A, Behringer RR. Requirement of Lim1 for female reproductive tract development. Development 2004;131:539-549.

34. Masse J, Watrin T, Laurent A, Deschamps S, Guerrier D, Pellerin I. The developing female genital tract: from genetics to epigenetics. Int J Dev Biol 2009;53:411-424.

35. Burel A, Mouchel T, Odent S, et al. Role of HOXA7 to HOXA13 and PBX1 genes in various forms of MRKH syndrome (congenital absence of uterus and vagina). $J$ Negat Results Biomed 2006;5:4.

36. Blaschke RJ, Rappold G. The pseudoautosomal regions, SHOX and disease. Curr Opin Genet Dev 2006;16:233-239.

37. Benito-Sanz S, Gorbenko del Blanco D, Huber C, et al Characterization of SHOX deletions in Leri-Weill dyschondrosteosis (LWD) reveals genetic heterogeneity and no recombination hotspots. Am J Hum Genet 2006;79: 409-414; author reply 414

38. Campos-Barros A, Benito-Sanz S, Ross JL, Zinn AR, Heath KE. Compound heterozygosity of SHOX-encompassing and downstream PAR1 deletions results in Langer mesomelic dysplasia (LMD). Am J Med Genet A 2007; 143A:933-938.

39. Grigelioniene G, Schoumans J, Neumeyer L, et al. Analysis of short stature homeobox-containing gene (SHOX) and auxological phenotype in dyschondrosteosis and isolated Madelung deformity. Hum Genet 2001; 109:551-558.

40. Huber C, Cusin V, Le Merrer M, et al. SHOX point mutations in dyschondrosteosis. J Med Genet 2001;38:323.

41. Jorge AA, Souza SC, Nishi MY, et al. SHOX mutations in idiopathic short stature and Leri-Weill dyschondrosteosis: frequency and phenotypic variability. Clin Endocrinol 2007;66:130-135.

42. Mutesa L, Vanbellinghen JF, Hellin AC, et al. Deletion of Xpter encompassing the SHOX gene and PAR1 region in familial patients with LeriWeill Dyschondrosteosis syndrome. Genet Couns 2009;20:9-17.

43. Shears DJ, Vassal HJ, Goodman FR, et al. Mutation and deletion of the pseudoautosomal gene SHOX cause Leri-Weill dyschondrosteosis. Nat Genet 1998;19:70-73

44. Roos L, Brondum Nielsen K, Tumer Z. A duplication encompassing the SHOX gene and the downstream evolutionarily conserved sequences. Am J Med Genet A 2009;149A:2900-2901.

45. Tachdjian G, Aboura A, Portnoi MF, et al. Cryptic Xp duplication including the SHOX gene in a woman with $46, \mathrm{X}, \operatorname{del}(\mathrm{X})(\mathrm{q} 21.31)$ and premature ovarian failure. Hum Reprod 2008;23:222-226.

46. Thomas NS, Harvey JF, Bunyan DJ, et al. Clinical and molecular characterization of duplications encompassing the human SHOX gene reveal a variable effect on stature. Am J Med Genet A 2009;149A:1407-1414. 